\title{
Female students are the most psychologically affected by the COVID-19 outbreak: a case study in an academic community in Brazil
}

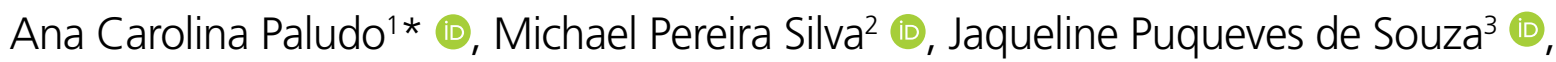

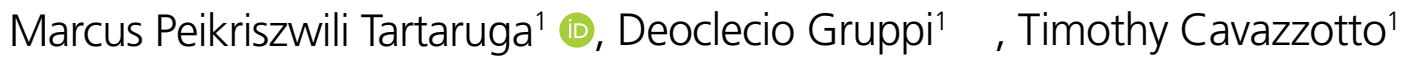

\section{SUMMARY}

OBJECTIVE: The study evaluates psychological responses to the COVID-19 outbreak in the students, professors, and staff due to the social distancing and transition of the classroom activities through online learning.

METHODS: 518 participants from a University community in Brazil answered an online survey with questions related to demographic data, psychological responses, and preventive measures. Absolute and relative frequencies described the sample, Chi-square and z-test tested associations between the variables, adopting $p<0.05$.

RESULTS: Female (71.20\%), young age -18 to 35 years (82.60\%), students (76.10\%), living in a family with 1 to 3 members during quarantine $(55.40 \%)$ were more prevalent respondents. Women, young age, and students had a significantly higher rate of negative feelings in all psychological questions. Curiously, negative feelings during social distances affect the participants, independent of living quarantine alone or with family/friends during the COVID-19 outbreak.

CONCLUSIONS: Our findings demonstrated that the COVID-19 outbreak affected the psychological responses in the Brazilian academic community, also, women, young age, and students appear to be a risk group to negative psychological responses. The long-term quarantine due to the COVID-19 pandemic may cause further worsening in the psychological responses, especially in those in the risk group. KEYWORDS: COVID-19 pandemic. Disease Outbreak. Quarantine. Psychological stress. Students.

\section{INTRODUCTION}

Nowadays, a severe acute respiratory syndrome (SARS), known as Coronavirus disease 2019 (COVID-19) quarantined the majority of countries. SARS-COVID-19 was first identified in December 2019 in the city of Wuhan, located in central China, and had spread worldwide ${ }^{1}$. Because of its widespread transmission, recognized as a pandemic disease by World Health Organization (WHO), measures to limit viral transmission and minimize contact with people infected by COVID-19, such as social distancing, have been recommended worldwide and imposed in some countries.
Based on the negative effect of quarantine, as reported elsewhere ${ }^{2,3}$ and its uncertain ending date, the scientific community has published valuable recommendations and strategies regarding the possible effect of quarantine and social isolation on mental health ${ }^{4,5}$ and psychological impact ${ }^{6}$. Moreover, recent studies demonstrated psychological responses to the COVID19 outbreak in Chinese ${ }^{7}$, Italian ${ }^{8,9}$ and students from South India $^{10}$, Bangladeshi ${ }^{11}$ and so one ${ }^{12}$.

The academic environment per se has already demonstrated to be stressful for professors and both graduate and undergraduate students, demonstrating a negative relationship with

\footnotetext{
'Universidade Estadual do Centro-Oeste, Departamento de Educação Física - Guarapuava (PR), Brazil.

${ }^{2}$ Universidade Federal do Rio Grande, Escola de Medicine - Rio Grande (RS), Brazil.

${ }^{3}$ Centro Universitário UniGuairacá, Departamento de Psicologia - Guarapuava (PR), Brazil.

*Corresponding author: anacpaludo@gmail.com

Conflicts of interest: the authors declare there is no conflicts of interest. Funding: none.

Received on February 10, 2021. Accepted on March 14, 2021.
} 
wellbeing and mental health ${ }^{13-15}$. Consequently, considering the quarantine and social isolation condition plus a new challenge of online learning, the psychological responses could be exacerbated in the University community. The main aim of this study was to evaluate the psychological responses to the COVID-19 outbreak in students, professors, and staff from a Brazilian University.

\section{METHODS}

\section{Participants}

A total of 526 respondents participated in the survey, and 518 were part of the final sample. Inclusion criteria were: being a member of the University selected (student, professor, or staff), being home-quarantined, and 18 years older. The local ethics committee approved the study (protocol number 4,002,656). Informed consent was acquired online, in the first part of the survey.

\section{Procedures}

An online survey platform with a designated link was sent to the University community after one month of quarantine. We used social media and institutional email to reach a large number of university members. The survey was completed from $1^{\text {st }}$ to May 30th, 2020. This study is a part of a more comprehensive research project intituled "COVID-19: Psychological and behavioral impacts of social isolation in the university community in a Midwest State of Paraná - Brazil”.

\section{Measures}

Descript data from sociodemographic questions were obtained through open and close-ended questions regarding the participants' age, biological sex, position (student, professor, or staff), number of members living together during quarantine, and contact with someone diagnosed with COVID-19. Moreover, behavioral responses as food consumption, sedentary behavior, and physical activities also were asked.

Psychological responses were measured using some items from the SELF-Reporting Questionnaire (SRQ-20) described in Table 1. The SQR-20 is a reliable tool in Portuguese ${ }^{16}$ that assess mental disorder such as depression and anxiety, include the questions Q1, Q2, Q3, Q4, Q7, and Q9. Also, questions regarding preventive measures were asked (Q5 and Q8). Participants should answer "frequently," "sometimes," or "never" for each question.

\section{Statistical analysis}

We used absolute and relative frequencies to describe demographic characteristics, psychological responses, and preventive measures. Chi-square and z-test tested the association between psychological responses and demographic characteristics. All the statistical analyses were performed using SPSS version 25.0, adopting $\mathrm{p}<0.05$.

\section{RESULTS}

The majority of the respondents were female $(71,2 \%)$, aged between 18 and 35 years $(82,6 \%)$, students $(76,1 \%)$, living in a family with 1 to 3 members during quarantine (55,4\%). $37 \%$ left the city at the beginning of the quarantine, and only 10 (all students) had a family or friend diagnosed with COVID-19.

The behavioral and preventive responses overall are displayed in Figure 1. At least $5 \%$ of the sample were quarantined alone; $52 \%$ of the women were eating more than normal, and $9-11 \%$ of the participants increased alcohol consumption. Women reported $2 \mathrm{~h}$ more in front of the TV and cell phone compared to men. The majority of respondents answered "sometimes" for the presence

Table 1. Psychological and preventive questions.

\begin{tabular}{l|c} 
Q1 & Do you feel nervous, tense, or worried more than usual? \\
\hline Q2 & Do you have trouble thinking clearly? \\
\hline Q3 & Do you find it difficult to enjoy your daily activities? \\
\hline Q4 & Do you find it difficult to make decisions? \\
\hline Q5 & $\begin{array}{c}\text { Are you using preventive measures such as wearing masks, using hand } \\
\text { sanitizer, and washing hands and clothes when you go outside? }\end{array}$ \\
\hline Q6 & Do you find it difficult to work home-office? \\
\hline Q7 & Have you lost interest in things? \\
\hline Q8 & How often are you going outside? \\
\hline Q9 & Do you feel tired more than usual?
\end{tabular}


of psychological parameters in all questions. Questions about feeling nervous, tense, or worried (Q1) and feeling tired more than usual (Q9) had the highest frequencies of "frequently" amongst the psychological questions. For preventive measures, almost all respondents are using preventive measures such as wearing masks, using hand sanitizer, and washing hands "frequently" (Q5), and the majority are going outside "sometimes" (Q8).

Table 2 shows the association between psychological responses and preventive measures with sex, age, education, and quarantine living environment. Considering the biological sex, females demonstrated a significantly higher frequency of negative feelings for all psychological questions than men. Similar responses were shown by the youngest (18-35 years old) compared to the oldest (more than 35 years old), and graduate and undergraduate students compared to professors and staff. No significant association was found regarding living quarantine conditions for the number of family members and psychological responses.

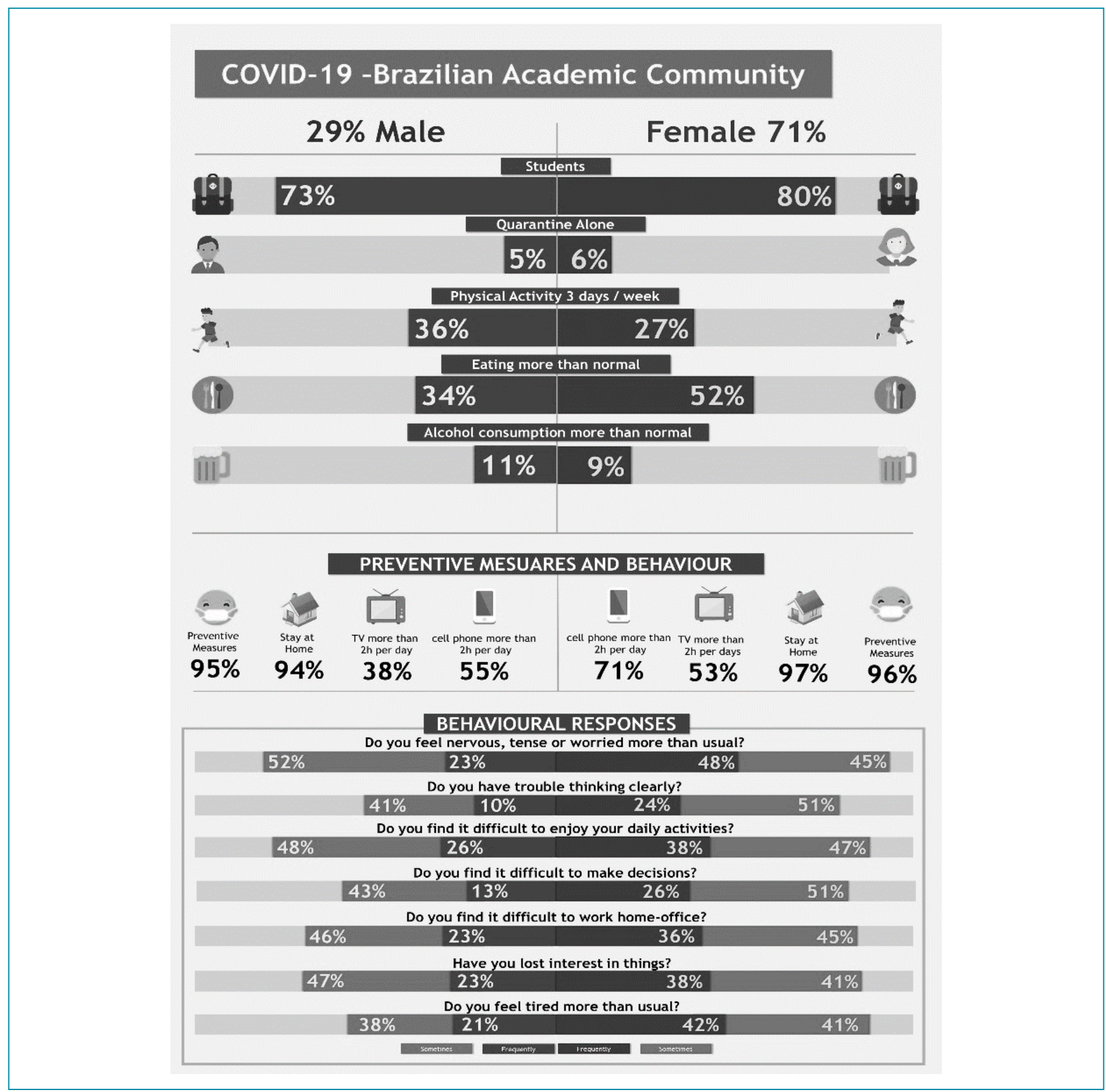

Figure 1. Infographic of the overall responses. 
Table 2. Psychological and preventive measures separated by sex, age, education, and quarantine living condition ( $\mathrm{n}=518$ ).

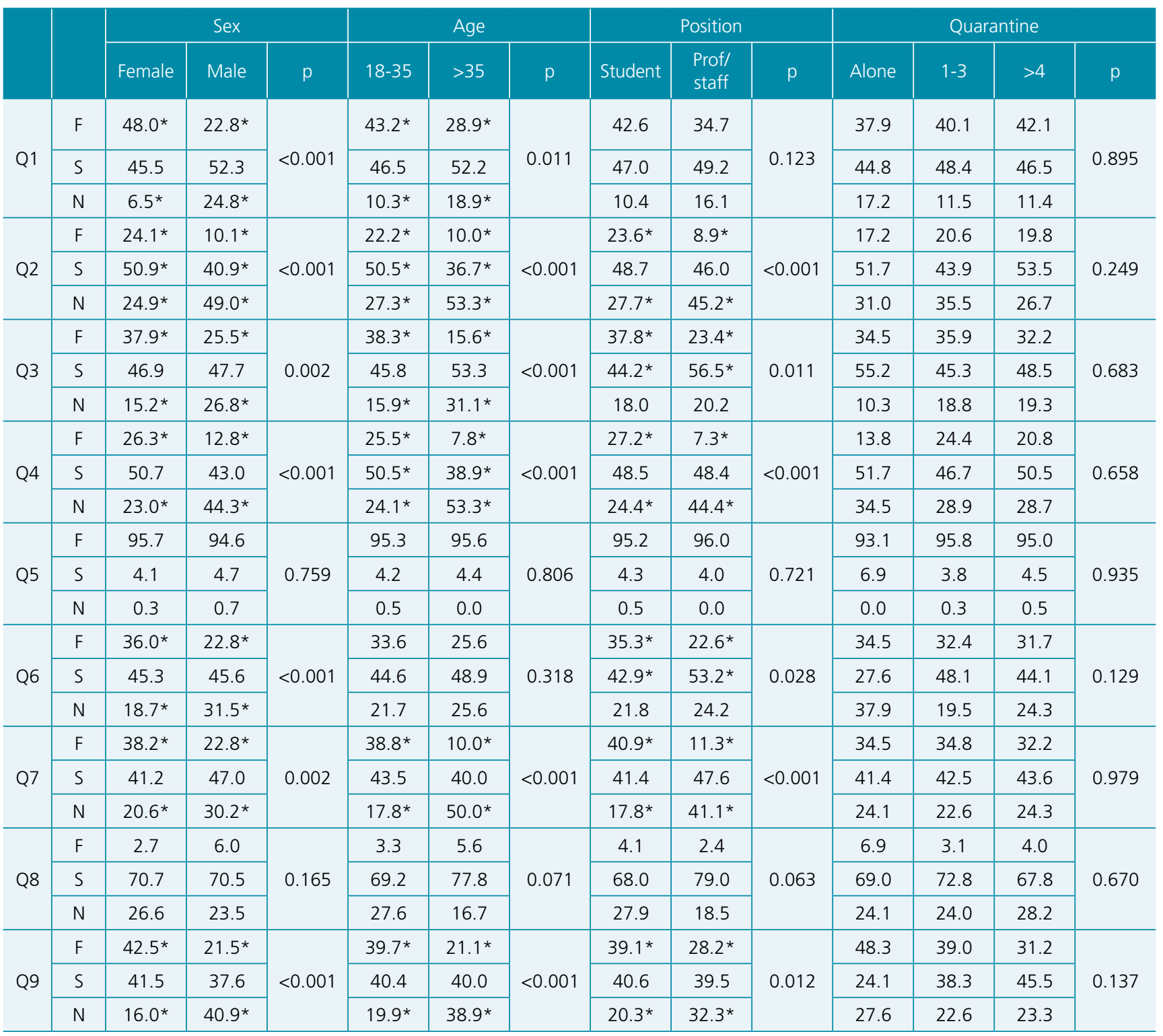

p: Chi-square. *Significant differences by z-test for sub-groups; F: Frequently; S: Sometimes; N: Never.

\section{DISCUSSION}

The main aim of the present study was to evaluate the psychological responses due to COVID-19 outbreak in students, professor, and staff from a Brazilian University and the main findings were:

1) Female, young age (18-35 years old) and students were most sensible to present frequently negative psychological responses compared to their counterparts;

2) Independently of spend quarantine alone or with more than 4 people, the psychological responses are similar; and

3) Majority of the academic population are using preventive measures (wearing mask, washing hands...) and going outside "sometimes".
The results of the current study indicated that females, young age, and students were associated with "frequently" negative psychological responses. This finding has been presented in recent studies during the COVID-19 outbreak. Female and younger than 30 years appeared to be risk factors for negative psychological responses in Italy's population ${ }^{8,9}$. In China, data suggest that females and students suffered significant psychological impacts and a higher level of stress, anxiety, and depression 7 . Indeed, women tend to be more vulnerable to experiencing psychological distress as well as more change to developing post-traumatic symptoms, as evidenced in the literature ${ }^{17}$. Therefore, during the quarantine period, it seems that women suffer more distress than men, and this gender difference 
can be explained for several reasons, from behavioral to physiological factors, as discussed by Song et al. ${ }^{18}$.

Regarding young people, participants who are 18 to 35 years old showed a higher frequency of "frequently" negative psychological responses than those with more than 35 years old. A similar response was found in the Chinese population, where younger participants ( $<35$ years) were more likely to develop anxiety and depressive symptoms during the COVID-19 outbreak than older participants ( $\geq 35$ years) (AOR=1.65, 95\%CI 1.49-2.02) ${ }^{7}$. As discussed elsewhere ${ }^{8}$, the negative psychological responses and higher anxiety in younger people may be explained due to easy and great access to information through social media ${ }^{19}$. Literature demonstrated that in normal conditions, the communication load resulting from internet multitasking is significantly related to increasing perceived $s^{2}{ }^{20} s^{20}$; therefore, these amounts of information can trigger negative psychological responses.

Lastly, our results showed that graduates and undergraduates present "frequently" negative psychological responses compared to professors and staff. This finding corresponds with those students in Bangladesh ( $\mathrm{n}=505$ college and university) in which $69.3 \%$ of students reported mild to severe level of psychological impact due to the COVID-19 outbreak, and additionally, university students had higher psychological impacts than college students ${ }^{11}$. Among Indian pharmacy students, $18 \%$ reported extremely severe depression, and about $27.5 \%$ with severe anxiety, and about $12.5 \%$ with severe stress $^{10}$. This response can be explained by uncertainty of academic progression and postponement of examinations, leading to a stressor factor in students mind ${ }^{21}$, especially in graduating final year students due to uncertainty about the pandemic effect may have increased their worry about graduating, finding a job, or enrolling in further study ${ }^{22}$.

Taken together, females and students have demonstrated a considerable risk of adverse psychological responses in normal conditions. Recently, a longitudinal study with Chinese college students reported that female students suered from significantly higher levels of anxiety than their male counterparts on average ${ }^{23}$. In Brazil, a recent study with university students $(\mathrm{n}=1,827)$ also demonstrated that $32 \%$ of students presented a major depressive episode. The major depressive episode was more frequent among females, aged between 21 and 23 years, showing a risk of $60 \%$ to present depressive episode $^{24}$. Therefore, the need for intervention in this specific group is necessary to promote a possible understanding of the situation.

Despite the present study be one of the first to evaluate the psychological effect of the COVID-19 outbreak in a Brazilian University community, it is not without limitations and caution regarding the generalization of our findings is recommended. We used an online convenience sampling strategy, which required participants' access to the internet. It limited the participation of those who do not have internet access. The sample does not represent all the University community, limiting the generalizability of our findings. Finally, this study does not use a specific tool to evaluate psychological distress or anxiety and depression; therefore, we cannot classify the severity of these domains during the quarantine period. However, the current data, together with recent studies, suggest that the recent quarantine due to COVID-19 outbreak affect the psychological responses in people, especially in female, young aged, and students.

\section{CONCLUSIONS}

During almost two months of quarantine and social isolation due to COVID-19, in Brazil, an academic community demonstrated to be affected by negative psychological responses. Female gender, young age, and student seem to be the group with the major psychological impact of the outbreak. The results present a general picture of the psychological impact of the COVID-19 outbreak on students, professors, and staff in Brazil. Attention is required from public health authorities and members of the academic community, to cope with this situation.

\section{ACKNOWLEDGMENTS}

The authors wish to acknowledge the University's support and the committed participation of all students, professors, and staff.

\section{AUTHORS' CONTRIBUTIONS}

ACP: Conceptualization, Funding acquisition, Investigation, Methodology, Project administration, Resources, Supervision, Visualization, Writing - original draft, Writing - review \& editing. MPS: Conceptualization, Funding acquisition, Investigation, Methodology, Project administration, Resources, Supervision, Visualization, Writing - original draft, Writing - review \& editing. JP: Conceptualization, Methodology, Visualization, Writing - review \& editing. DG: Conceptualization, Writing - review \& editing. MPT: Conceptualization, Writing - review \& editing. TC: Conceptualization, Data curation, Formal analysis, Funding acquisition, Investigation, Methodology, Project administration, Resources, Writing - original draft, Writing - review \& editing. All authors have read and agreed to the published version of the manuscript.

\section{ETHICAL ASPECTS}

The project was reviewed and approved by the Research Ethics Committee of the UNICENTRO - University (protocol number 4.002.656).

\section{DATA AVAILABILITY STATEMENT}

Data associated with this publication is archived in the Git hub Integration Platform by link: https:/github.com/timcavazzotto/ Psycho_Response_Covid19_Unicentro. 


\section{REFERENCES}

1. World Health Organization. Coronavirus disease (COVID-2019). Situation reports. Coronavirus disease (COVID-19) weekly epidemiological update and weekly operational update. [cited on $2000 \mathrm{Apr}$ 1]. Available from: https://www.who.int/ emergencies/diseases/novel-coronavirus-2019/situation-reports.

2. Reynolds DL, Garay JR, Deamond SL, Moran MK, Gold W, Styra R. Understanding, compliance and psychological impact of the SARS quarantine experience. Epidemiol Infect. 2008;136(7):9971007. https://doi.org/10.1017/S0950268807009156

3. Jeong H, Yim HW, Song YJ, Ki M, Min JA, Cho J, et al. Mental health status of people isolated due to middle east respiratory syndrome. Epidemiol Health. 2016;38:e2016048. https://doi. org/10.4178/epih.e2016048.

4. Ornell F, Schuch JB, Sordi AO, Kessler FHP. "Pandemic fear" and COVID-19: mental health burden and strategies. Braz J Psychiatry. 2020;42(3):232-35. https://doi.org/10.1590/15164446-2020-0008

5. Hou C, Chen J, Zhou Y, Hay L, Yuan J, He S, et al. The effectiveness of quarantine of Wuhan city against the corona virus disease 2019 (COVID-19): a well-mixed SEIR model analysis. J Med Virol. 2020;92(7):841-8. https://doi.org/10.1002/ jmv.25827

6. Brooks SK, Webster RK, Smith LE, Woodland L, Wessely S, Greenberg N, et al. The psychological impact of quarantine and how to reduce it: rapid review of the evidence. Lancet. 2020;395(10227):912-20. https://doi.org/10.1016/S01406736(20)30460-8

7. Wang C, Pan R, Wan X, Tan Y, Xu L, Ho CS, et al. Immediate psychological responses and associated factors during the initial stage of the 2019 coronavirus disease (COVID-19) epidemic among the general population in China. Int J Environ Res Public Health. 2020;17(5):1729. https://doi.org/10.3390/ijerph17051729

8. Mazza C, Ricci E, Biondi S, Colasanti M, Ferracuti S, Napoli C, et al. A nationwide survey of psychological distress among italian people during the COVID-19 pandemic: immediate psychological responses and associated factors. Int J Environ Res Public Health. 2020;17(9):3165. https://doi.org/10.3390/ijerph17093165

9. Casagrande M, Favieri F, Tambelli R, Forte $G$. The enemy who sealed the world: effects quarantine due to the COVID-19 on sleep quality, anxiety, and psychological distress in the Italian population. Sleep Med. 2020;75:12-20. https://doi. org/10.1016/j.sleep.2020.05.011

10. Vidyadhara S, Chakravarthy A, Pramod Kumar A, Sri Harsha C, Rahul R. Mental health status among the south Indian pharmacy students during covid-19 pandemic quarantine period: a cross-sectional study. MedRxiv. 2020;20093708. https://doi.org/10.1101/2020.05.08.20093708

11. Khan AH, Sultana MS, Hossain S, Hasan MT, Ahmed HU, Sikder MT. The impact of COVID-19 pandemic on mental health \& wellbeing among home-quarantined Bangladeshi students: a cross-sectional pilot study. J Affect Disord. 2020;277:121-8. https://doi.org/10.1016/j.jad.2020.07.135

12. Ammar A, Mueller $\mathrm{P}$, Trabelsi $\mathrm{K}$, Chtourou $\mathrm{H}$, Boukhris $O$, Masmoudi L, et al. Emotional consequences of
COVID-19 home confinement: the ECLB-COVID19 multicenter study. MedRxiv. 2020;20091058. https://doi. org/10.1101/2020.05.05.20091058

13. Pace F, D'Urso G, Zappulla C, Pace U. The relation between workload and personal well-being among university professors. Curr Psychol. 2021;40:3417-24. https://doi.org/10.1007/ s12144-019-00294-x

14. Wyatt T, Oswalt SB. Comparing mental health issues among undergraduate and graduate students. American Journal of Health Education. 2013;44(2):96-107. https://doi.org/10.10 80/19325037.2013.764248

15. Kausar, R. Perceived stress, academic workloads and use of coping strategies by university students. Journal of Behavioural Sciences. 2010;20:31-45.

16. Iacoponi E, Mari JJ. Reability and factor structure of the portuguese version of self-reporting questionnaire. Int J Soc Psychiatry. 1989;35(3):213-22. https://doi. org/10.1177/002076408903500301

17. Sareen J, Erickson J, Medved MI, Asmundson GJG, Enns MW, Stein M, et al. Risk factors for post-injury mental health problems. Depress Anxiety. 2013;30(4):321-7. https://doi. org/10.1002/da.22077

18. Song K, Li T, Luo D, Hou F, Bi F, Terry DS, et al. Psychological stress and gender differences during COVID-19 pandemic in chinese population. MedRxiv. 2020. https://doi. org/10.1101/2020.04.29.20084061

19. Zhang MWB, Ho CSH, Fang P, Lu Y, Ho RCM. Methodology of developing a smartphone application for crisis research and its clinical application. Technol Health Care. 2014;22(4):547-59. https://doi.org/10.3233/THC-140819

20. Reinecke L, Aufenanger S, Beutel ME, Dreier M, Quiring $O$, Stark B, et al. Digital stress over the life span: the effects of communication load and internet multitasking on perceived stress and psychological health impairments in a German probability sample. Media Psychology. 2017;20(1):90-115. https://doi.org/10.1080/15213269.2015.1121832

21. Roy D, Tripathy S, Kar SK, Sharma N, Verma SK, Kaushal V. Study of knowledge, attitude, anxiety \& perceived mental healthcare need in Indian population during COVID-19 pandemic. Asian J Psychiatr. 2020;51:102083. https://doi. org/10.1016/j.ajp.2020.102083

22. Tang W, Hu T, Hu B, Jin C, Wang G, Xie C, et al. Prevalence and correlates of PTSD and depressive symptoms one month after the outbreak of the COVID-19 epidemic in a sample of home-quarantined Chinese university students. J Affect Disord. 2020;274:1-7. https://doi.org/10.1016/j.jad.2020.05.009

23. Gao W, Ping S, Liu X. Gender differences in depression, anxiety, and stress among college students: a longitudinal study from China. J Affect Disord. 2020;263:292-300. https:// doi.org/10.1016/j.jad.2019.11.121

24. Flesch BD, Houvèssou GM, Mun hoz TN, Fassa AG. Major depressive episode among university students in Southern Brazil. Rev Saude Publica. 2020;54:11. https://doi.org/10.11606/ s1518-8787.2020054001540 